\title{
E OS PESQUISADORES BRASILEIROS QUE PRATICAM GROUNDED THEORY: 0 QUE FAZEM?
}

\author{
AND THE BRAZILIAN RESEARCHERS WHO USE GROUNDED THEORY:
} WHAT DO THEY DO?

\section{Irene Raguenet Troccoli ${ }^{1}$}

RESUM0: Investigar sobre o uso da Grounded Theory (GT) no campo da Administração de Empresas é desafiador. Isso porque, se há alguns estudos que discutem este meio de pesquisa, muito poucos de fato dele lançam mão no tratamento dos dados e das evidências. O propósito deste estudo bibliométrico foi investigar as formas de utilização da GT em amostra de artigos brasileiros da área de Administração de Empresas, comparando-as com as concepções originais dos autores da teoria. A conclusão é de que a GT não é utilizada de forma única, embora seus princípios básicos sejam respeitados. Isto reproduz os resultados de pesquisa anterior, executada com amostra de artigos de periódicos não brasileiros, e que foi utilizada como matriz inspiradora desta investigação.

PALAVRAS-CHAVE: Grounded theory. Bibliometria.

ABSTRACT: It is challeging to investigate the use of Grounded Theory (GT) in Business Administration, because some studies discuss this research means, but very few actually use it to treat data The purpose of this bibliometric study was to investigate how GT was used in a sample of Brazilian business administration articles, compared to its original guidelines. The conclusion is that GT is not used in a single way, although its basic principles are respected. This replicates the results of a previous research, carried out with a sample of articles from non-Brazilian academic magazines, that was used as an inspirational matrix for this paper.

KEYWORDS: Grounded theory. Bibliometrics.

\footnotetext{
${ }^{1}$ Economista pela Universidade Federal do Rio de Janeiro - UFRJ e Doutora e mestre em Administração de Empresas pela Pontifícia Universidade Católica do Rio de Janeiro -PUC-RJ. Consultora-associada à Fundação Getulio Vargas. Analista de desenvolvimento estratégico da Embratel. Rio de Janeiro-RJBrasil. E-mail: irene.troccoli@estacio.br

Recebido em: 23/06/2013 - Aceito em: 24/01/2014.
} 


\section{INTRODUÇÃ̃o}

A Grounded Theory (GT), também conhecida no Brasil como teoria fundamentada em dados, se originou no interacionismo simbólico, paradigma que sustenta que os indivíduos se envolvem em um mundo que exige a interação reflexiva em contraponto à resposta ambiental. Assim, o comportamento depende das metas do indivíduo, é derivado da interação social - elemento altamente simbólico em si - e envolve várias formas de comunicação, tanto verbais como não verbais. Em outras palavras, a GT é adequada ao estudo de qualquer comportamento que apresente algum elemento interacional (SCHWANDT, 1994).

No entanto, embora o interacionismo simbólico fosse considerado fundamental no campo da sociologia em meados do século XX, à época pouco se sabia sobre como usar seus conceitos e construtos na condução de pesquisas. Reforçando o caldo de cultura daquele momento, grande parte daquilo que provinha deste paradigma convivia com ataques acadêmicos aos meios qualitativos de investigação, entendidos como pouco científicos e de baixo rigor. Em outras palavras, havia a necessidade de uma metodologia capaz de controlar e de validar o processo de construção da teoria.

Foi neste período que dois sociólogos americanos, Barney Glaser e Anselm Strauss, desenvolveram um processo mais sistemático e definido para a coleta e a análise de evidências qualitativas. Denominado de Grounded Theory (GT), seu propósito era buscar a construção teórica a partir das palavras e das ações dos indivíduos estudados.

Não por acaso, a riqueza desta metodologia tem sido amplamente atribuída a três elementos: às influências das escolas sociológicas de interacionismo simbólico, à etnografia e à sólida formação de Glaser na teorização formal. Por conseguinte, a GT é adequada para o estudo de qualquer comportamento que apresente um elemento de interação com ele (GOULDING, 2004).

A GT prega que, uma vez que uma área de pesquisa tenha sido identificada, o investigador deve entrar no campo o mais rapidamente possível. Isto implica que a literatura não se esgota antes da pesquisa, como em muitos estudos, mas sim que a coleta de informações deve ser um processo iterativo, indutivo e interacional, 
alimentado pela análise e pela interpretação simultâneas e emergentes. Em resumo, o desenvolvimento da teoria se faz à medida que o pesquisador lança mão de teorias e da literatura pré-existentes que sejam relevantes para os conceitos - que, por sua vez, irão emergir com base nestas informações.

Este aspecto, contudo, não raro tem sido erroneamente interpretado por aqueles que lidam com a GT, a partir da relativa confusão a respeito da indução, princípio muito presente na teoria. Um equívoco comum é que o pesquisador deva entrar em campo ignorante de qualquer teoria ou literatura relacionada ao fenômeno, devendo aguardar que a teoria surja apenas das evidências primárias. Tais percepções resultaram em acusações de que os criadores da GT teriam "enganado" seus seguidores, pois que teriam pregado a desnecessidade da teoria - embora eles mesmos tivessem ido a campo plenos de conceitos e de experiências (GOULDING, 2002).

Isto, na verdade, não se aplica. Ao contrário, o rigor da abordagem proporcionado pela GT força o pesquisador a olhar para além do superficial, levando-o a aprofundar a interpretação dos fatos antes de desenvolver conceitos finais, e a demonstrar estes conceitos por meio de dados e de explicações comprováveis.

Contudo, não raro se observam problemas na aplicação da GT, geralmente derivados da falta de conhecimento a respeito dos seus princípios mais básicos. Tal é o caso, por exemplo, da pesquisa de Mullins e Roessier (1998), cujas falhas incluíram ignorar a comparação constante, um dos pilares da metodologia da GT.

Não foi por outro motivo que Jacobus, Souza e Bitencourt (2012), tendo observado o uso considerável da GT em periódicos estrangeiros com elevado índice de impacto, decidiram investigar alguns aspectos que, do seu ponto de vista, indicariam se autores de uma dada amostra de artigos não brasileiros convergiriam no uso da GT tanto quanto o possível para garantir um mínimo grau de estabilidade ao conceito da teoria originalmente pregado por Glaser e Strauss (1967): 1) quais as justificativas dos autores para a utilização da GT como meio de pesquisa; 2) se houve preocupação em diminuir o risco da tendenciosidade das informações; 3) se houve empenho em detalhar o processo de codificação; 4) se houve o emprego constante do método comparativo; 5) qual a abordagem (qualitativa ou quantitativa) utilizada; 6) qual a relação entre revisão de literatura e as etapas de coleta e de análise dos dados e ou das evidências; e 7) se o propósito original da GT - gerar teoria - foi realmente considerado. 
Portanto, aqueles três autores levantaram, na base de dados Business Source Complete, amostra de 45 artigos que continham o termo grounded theory em seu abstract, e que incluíam periódicos com alto índice de impacto, tais como Organization Science, MIS Quarterly e Academy of Management Journal.

O item do artigo que traz os resultados desta investigação sugestivamente denomina-se "Grounded Theory aplicada à área de Administração: diversidade e contradições" (JACOBUS; SOUZA; BITENCOURT, 2012, p. 8). Resumidamente, as descobertas da pesquisa foram as seguintes, relativamente àqueles sete pontos avaliados:

1) Foram salientadas quatro justificativas para o uso da GT como meio de pesquisa: a) ela garante que será possível gerar teoria, e que essa, por sua vez, não será trivial; b) ela é “... particularmente adequada em áreas em que o desenvolvimento teórico ainda é muito limitado" (p. 8); c) ela possui rigor especial no que tange à "... coleta, análise dos dados e consequente geração de teoria" (p. 8); e d) ela é adequada para ser aplicada a fenômenos que são altamente determinados pelo contexto organizacional em que estão inseridos, onde se destacam as percepções dos sujeitos que vivem esse fenômeno.

2) Em $64 \%$ da amostra houve referência direta ou indireta à triangulação de dados, confirmando a preocupação com a confiabilidade das análises.

3) Não houve empenho em detalhar o processo de codificação e de análise dos dados e das evidências.

4) "Em quase todos os artigos" (JACOBUS; SOUZA; BITENCOURT, 2012, p. 9) da amostra a comparação constante é citada, ocorrendo, por exemplo, “...entre os insights empíricos emergentes e sua teoria genérica da capacidade organizacional" (JACOBUS; SOUZA; BITENCOURT, 2012, p. 9).

5) $\mathrm{O}$ foco foi dirigido à abordagem quantitativa, com apenas quatro artigos da amostra tendo utilizado a abordagem quali-quanti.

6) Via de regra, a literatura existente funcionou como gênese para a formulação do problema de pesquisa.

7) A quase totalidade dos 45 artigos “...não produzem teoria plena, mas aproximações teóricas” (JACOBUS; SOUZA; BITENCOURT, 2012, p. 10). 
Se a ideia norteadora da pesquisa de Jacobus, Souza e Bittencourt (2012) é simples, nem por isso é menos relevante. Na conclusão de seu trabalho, eles colocam que foi ratificada sua suspeita de que

... não há uma "grounded theory" objetivamente material e unívoca, mas um conceito prototípico que se realiza de formas ligeiramente diferentes, ainda que mantenha uma essência que justifica o uso de uma mesma denominação. (JACOBUS; SOUZA; BITENCOURT, 2012, p. 11).

Em vista desses resultados, surgiu a curiosidade que se transformou na gênese deste artigo: se este foi o comportamento de autores estrangeiros cujos trabalhos podem ser considerados relevantes, qual seria o resultado de pesquisa semelhante no caso de autores brasileiros veiculados em periódicos nacionais destacados no meio acadêmico da Administração de Empresas?

Para encontrar a resposta a esta pergunta, esse artigo traz, além desta introdução, três outros itens: a metodologia seguida, os resultados obtidos e a conclusão.

\section{METODOLOGIA}

A abordagem adotada foi quantitativa, constituindo-se como pesquisa bibliométrica quanto aos meios e comparativa quanto aos fins. Para o levantamento das evidências foi seguida a metodologia aplicada por Jacobus, Souza e Bitencourt (2012), com algumas adaptações.

A amostra aqui estudada obviamente foi diferente, pois o universo visado foi o de trabalhos veiculados em periódicos brasileiros. No caso, o levantamento da amostra foi feito inicialmente consultando-se a base Scielo $^{2}$, onde se buscou o termo grounded theory no campo denominado "todos os índices". O retorno foi de 14 artigos brasileiros, dos quais nove foram descartados ou por serem oriundos de periódicos fora da área de Administração, ou por serem dessa área, mas dizendo respeito a trabalhos teóricos referidos a questões puramente metodológicas. Com isso, permaneceram cinco artigos, cada um pertencente a um periódico diferente: Revista de Administração de Empresas

2 Sigla de Scientific Electronic Library Online, a Scielo é uma base de dados bibliográficos, disponível no endereço eletrônico $<$ http://www.scielo.org/php/index.php> 
(RAE), Revista de Administração Contemporânea (RAC), Revista de Administração Mackenzie (RAM), Organizações \& Sociedade (O\&S) e Brazilian Administration Review (BAR).

Dado o tamanho muito pequeno da amostra, optou-se por verificar se poderiam ser localizados outros artigos nas homepages dos mesmos cinco periódicos, por meio de busca das palavras-chave grounded theory, teoria fundamentada nos dados, e teoria fundamentada em dados. No caso da RAM, da O\&S, da BAR e da RAC, esta busca foi realizada usando-se a ferramenta de pesquisa nos resumos dos artigos. No caso da $\mathrm{RAE}^{3}$ a busca foi realizada junto às palavras-chave por não estar disponível a ferramenta de busca junto aos resumos.

O resultado desta segunda busca reproduziu os cinco artigos que já haviam sido encontrados por meio da base Scielo (da RAE, da RAC, da O\&S e da BAR), mas também revelou mais seis artigos, sendo três da O\&S, um da RAC, e dois da RAM. Com isso, a amostra final chegou a 12 artigos (ver Quadro 1).

Em seguida, cada um dos 11 artigos foi lido com o objetivo de, à semelhança do realizado por Jacobus, Souza e Bittencourt (2012), investigar: 1) quais as justificativas dos autores para a utilização da GT como meio de pesquisa; 2) se houve preocupação em garantir a confiabilidade das análises diminuindo o risco da tendenciosidade das informações; 3) se houve empenho em detalhar o processo de codificação; 4) se houve o emprego constante do método comparativo; 5) qual a abordagem (qualitativa ou quantitativa) utilizada; 6) qual a relação entre revisão de literatura e as etapas de coleta e de análise dos dados e ou das evidências; e 7) se o propósito original da GT - gerar teoria - foi realmente considerado ${ }^{4}$.

Para se operacionalizar essa investigação, por sua vez, foram montados sete quadros - um para cada um destes sete itens - com duas colunas cada. Em todos os sete quadros, na primeira coluna listaram-se os autores dos 11 trabalhos da amostra, enquanto a segunda coluna foi preenchida de forma particular em cada um dos quadros, ou seja, com os resultados da pesquisa para aquele item em especial. Em seguida, foi

\footnotetext{
3 A homepage aglutina as revistas RAE, RAE Eletrônica e GV Executivo.

${ }^{4}$ Vale notar que, embora Glaser e Strauss (1967) afirmem que a proposta primária da GT é a geração de teoria, Strauss e Corbin (1998) afirmam que seus procedimentos podem ser utilizados especificamente em um estudo sem necessariamente conduzir a uma teoria.
} 
analisado cada um dos sete resultados das 11 investigações, e elaborado o texto final das conclusões.

QUADRO 1 - Amostra pesquisada - Periódico de origem, referência completa do artigo, e forma(s) de localização

\begin{tabular}{|c|c|c|}
\hline $\begin{array}{c}\text { PERIÓDICO DE } \\
\text { ORIGEM }\end{array}$ & REFERÊNCIA DO ARTIGO & $\begin{array}{c}\text { FORMA(S) DE } \\
\text { LOCALIZAÇÃ̃ }\end{array}$ \\
\hline O\&S & $\begin{array}{l}\text { Pinto e Santos (2012) } \\
\text { Frezatti et al. (2011) } \\
\text { Zilber, Perez e Lex (2009) } \\
\text { Bacellar e Ikeda (2007) }\end{array}$ & $\begin{array}{l}\text { Base Scielo } \\
\text { Homepage da revista } \\
\text { Homepage da revista } \\
\text { Homepage da revista }\end{array}$ \\
\hline BAR & Petrini e Pozzebon (2010) & Base Scielo \\
\hline RAC & $\begin{array}{l}\text { Bandeira de Mello e Cunha (2004) } \\
\text { Saraiva et al. (2011) }\end{array}$ & $\begin{array}{l}\text { Base Scielo } \\
\text { Homepage da revista }\end{array}$ \\
\hline RAE & Cherman e Rocha Pinto (2013) & Base Scielo \\
\hline RAM & $\begin{array}{l}\text { Ikeda e Bacellar (2008) } \\
\text { Cruz e Zouain (2008) } \\
\text { Vasconcelos e Pinochet (2002) }\end{array}$ & $\begin{array}{l}\text { Base Scielo } \\
\text { Homepage da revista } \\
\text { Homepage da revista }\end{array}$ \\
\hline
\end{tabular}

Fonte: Elaboração própria

\section{RESULTADOS OBTIDOS}

3.1 Justificativas dos autores para a utilização da GT como meio de pesquisa, e consideração do propósito original da GT de gerar teoria

Tendo em vista que a gênese da própria GT é a criação de uma teoria, a análise deste ponto será feita aqui conjuntamente com o resultado da investigação sobre se os artigos da amostra claramente se propuseram a esta criação.

Dentre os 11 artigos, seis não geraram teoria, indicando que seus objetivos eram de outra natureza. O de Saraiva et al. (2011, p. 1017) era "conceituar estratégia de forma substantiva"; Cherman e Rocha Pinto (2013, p. 142) buscaram "responder quais processos são adotados pelos indivíduos para a valoração dos conhecimentos nas organizações" e "identificar os processos e mecanismos adotados pelos indivíduos para a valoração do conhecimento na organização"; e Cruz e Zouain (2008, p. p. 12) buscaram "identificar categorias que compõem e influenciam o desempenho exportador de três consórcios de exportação do segmento de moda praia".

Vale notar que os autores dos outros três artigos desta subamostra declararam explicitamente que seu objetivo não fora gerar teoria. Bacellar e Ikeda (2007, p. 153) colocam que “...é de fundamental importância deixar claro que o trabalho não tem como 
objetivo final a elaboração de uma teoria sobre o ensino de Marketing". Da mesma forma, Ikeda e Bacellar (2008, p. 143) dizem que seu objetivo de pesquisa de levantar a perspectiva de professores de Marketing em relação aos alunos se legitima pelo fato de que "Embora a finalidade da GT seja a construção de teorias, sua utilização não necessariamente precisa ficar restrita apenas aos pesquisadores que têm esse objetivo". Por último, Petrini e Pozzebon (2010, p. 362) informam claramente que o que construíram foi um "modelo conceitual”, e que acreditam que pesquisas futuras possam reforçar a relação entre esse modelo e teorias de mudança organizacional para, aí sim, desenvolver determinada teoria.

Então, qual teria sido a justificativa dos autores destes seis trabalhos para o uso da GT como meio de pesquisa, já que eles não geraram teoria?

Saraiva et al. (2011) não colocam uma explicação objetiva para esta escolha; limitam-se a comentar algumas características da GT, aparentemente para indicar que entendeu-as como as mais adequadas para seu estudo. Já Cherman e Rocha Pinto (2013, p. 145) indicam três motivos em especial para esta escolha: porque seria possível estender a afinidade filosófica do pragmatismo ao objeto da pesquisa, por causa do pragmatismo da lógica abdutiva, e porque a GT “(...) é um método explícito para analisar processos”. Quanto a Cruz e Zouain (2008), eles justificam o uso da GT por três ângulos: porque seu estudo não tinha hipóteses preconcebidas, porque havia pouca teoria a respeito do assunto pesquisado - muito embora as autoras não tenham chegado a gerar teoria - e porque este meio de pesquisa seria o mais adequado para o alcance do objetivo final, que era identificar categorias que influenciam as estratégias de marketing de um consórcio.

Quanto aos três artigos onde está explicitamente colocado que o objetivo não era criar teoria, no caso de Bacellar e Ikeda (2007) contraditoriamente o uso da GT foi justificado por não haver teorias específicas sobre o assunto; Ikeda e Bacellar (2008) dizem que seu interesse está simplesmente no uso de alguns dos procedimentos da GT para satisfazer seus objetivos de pesquisa; e Petrini e Pozzebon (2010) informam que sua opção pela GT deveu-se à ênfase que este meio de pesquisa coloca no aprendizado que emerge dos dados, e não de um ponto de vista teórico já existente.

Observe-se que a argumentação destes dois últimos converge com os achados de Zanin, Bach e Walter (2012) ao pesquisarem 48 estudos que utilizaram a GT e que 
foram veiculados nos eventos da Associação Nacional dos Programas de PósGraduação em Administração (ANPAD) no período de 1997 a 2011: embora ali a predominância tenha sido no sentido de usar a GT para a geração de uma nova teoria ou para gerar uma teoria a partir de outra existente, houve casos em que ela foi utilizada apenas como método de análise.

Voltando-se aos cinco artigos que geraram teoria suas motivações foram: 1) a GT vai além da etnografia, que, sozinha, teria sido incapaz de gerar teoria no estudo (PINTO; SANTOS, 2012); Bandeira de Mello e Cunha (2004, p. 160) ressaltaram alguns porquês da adequação da GT ao seu propósito de gerar teoria, tais como que ela “(...) oferece uma série de procedimentos que aumentam a credibilidade dos resultados e possibilitam sua posterior verificação e escrutínio público" e “(...) pelo fato de encorajar a criatividade e a descoberta de problemas multifacetados e relevantes para os envolvidos, ao mesmo tempo que atenua a subjetividade do pesquisador".

Já Frezatti et al. (2011) e Vasconcelos e Pinochet (2002) não colocam uma justificativa objetiva. No primeiro caso, limitam-se a mencionar os procedimentos clássicos da metodologia que foram abraçados na pesquisa. No segundo caso, indicam a adequação da GT conforme o tema que pesquisam é novo e o referencial teórico é parco.

Quanto a Zilber, Perez e Lex (2009) nada informaram a respeito, nem mesmo mencionando os procedimentos clássicos da GT.

\subsection{Preocupação em diminuir o risco da tendenciosidade das informações}

Na GT, é ressaltada a necessidade de cuidados extremos para se buscar a diminuição da tendenciosidade das informações, procedimento que ajuda a garantir a confiabilidade das análises. Assim, configura-se no delicado equilíbrio requerido do pesquisador quando este se divide entre o conhecimento prévio do assunto estudado e a manutenção de sua mente aberta a novos conceitos que emergem das informações.

$\mathrm{Na}$ amostra, quatro trabalhos exibiram passagem onde seus autores dizem explicitamente que se preocuparam em evitar possíveis vieses em suas pesquisas: Petrini e Pozzebon (2010), Bandeira de Mello e Cunha (2004), Pinto e Santos (2012), e Frezatti et al. (2011). 
No caso do penúltimo, está dito que “(...) o segundo autor, além de contribuir para a elaboração da discussão teórica, serviu como moderador ao longo do processo de pesquisa, questionando as interpretações e propondo novas formas de construção teórica" (PINTO; SANTOS, 2012, p. 423). Já Frezatti et al (2011, p. 450) dizem ter realizado “(...) avaliação e validação de dados, por meio da triangulação de dados e da triangulação conceitual (com a literatura)".

\subsection{Empenho em detalhar o processo de codificação}

Apenas três artigos da amostra trazem detalhes sobre como foi realizado processo de codificação: Frezatti et al. (2011), Bandeira de Mello e Cunha (2004) e Cherman e Rocha Pinto (2013).

A transcrição de um deles a respeito deste ponto exemplifica a importância que estes trabalhos imputaram a informar o leitor sobre este quesito:

O processo de codificação foi divido em três fases não lineares: codificação aberta, axial e seletiva. Após a identificação de categorias conceituais pela codificação aberta, a codificação axial examinou as relações entre categorias e subcategorias para explicitar causas e efeitos, condições intervenientes e estratégias de ação, que foram relacionadas em proposições. Finalmente, a codificação seletiva refinou e integrou todos os resultados, possibilitando a identificação da categoria central da teoria, a administração do risco. (BANDEIRA DE MELLO; CUNHA, 2004, p. 164)

\subsection{Emprego do método comparativo}

Neste quesito, vale ressaltar que se buscou, no levantamento bibliométrico, verificar se os artigos tinham, pelo menos, menção ao uso deste recurso, sem que fosse feita a crítica quanto ao procedimento neste caso ter sido completamente fiel àquele proposto por Glaser e Strauss (1967).

O que se observou foi que quatro trabalhos procederam desta forma: Bacellar e Ikeda (2007), Petrini e Pozzebon (2010), Bandeira de Mello e Cunha (2004), e Pinto e Santos (2012). No caso deste último os autores se preocuparam, inclusive em ressaltar e em justificar de forma veemente seu interesse por não abrirem mão deste procedimento: 
A comparação constante é o elemento fundamental da grounded theory - enquanto metodologia de pesquisa - uma vez que funciona como uma espécie de amálgama que interliga os processos de coleta seletiva dos dados (amostragem e saturação teórica), de análise (codificação e categorização) e de formulação (writing) da teoria (HAIG, 1995; EGAN, 2002). Fazer comparações é essencial para a análise dos dados na "nossa metodologia" (STRAUSS; CORBIN, 1998, p.78), não apenas para identificar e classificar incidentes (comparação incidente-incidente), mas também para estimular a reflexão sobre propriedades e dimensões de categorias conceituais mais "densas" (comparação teórica) e para (re)direcionar a amostragem teórica do estudo.

\subsection{Abordagem utilizada}

A totalidade dos trabalhos analisados indicou utilizar a abordagem qualitativa. Ou seja, não houve a utilização de nenhum recurso matemático-estatístico no tratamento das respectivas informações.

3.6 Relação entre revisão de literatura e as etapas de coleta e de análise dos dados e ou das evidências

Remetendo ao que foi dito no início do item 3 deste artigo, a avaliação, nos 11 artigos analisados, da relação entre revisão de literatura e as etapas de coleta e de análise dos dados e ou das evidências, pode ter sofrido interferência do fato de os periódicos indexados não raro demandarem que os autores sigam padrão de apresentação de artigos resultantes de pesquisas empíricas onde classicamente o referencial teórico se apresentando antes dos resultados da pesquisa.

Em outras palavras, não há como saber ao certo - a não ser que tal tenha sido dito de forma explícita - se as respectivas pesquisas maiores que geraram os 11 artigos seguiram o procedimento-padrão da GT, que é o de apresentar a teoria que deu suporte à investigação apenas após o resultado da pesquisa primária. De fato, esta situação foi observada no caso de Chermont e Rocha Pinto (2013, p. 146): no artigo, a revisão da literatura é colocada fisicamente antes da apresentação da pesquisa em si, mas as autoras se preocuparam em ressaltar, no item de metodologia, que, na pesquisa maior, 
(...) o referencial teórico referente à identificação e à IO [identidade organizacional], e suas relações com valoração do conhecimento, foi construído após a análise inicial dos dados emergentes do campo, na etapa de agrupamento dos códigos de primeira ordem em categorias.

Portanto, o que esta pesquisa bibliométrica mostrou foi que apenas três artigos da amostra ou apresentaram o referencial teórico após os resultados da pesquisa primária ou o apresentaram antes mas ressaltaram que a respectiva pesquisa maior seguiu, de fato, o preceito da GT: Pinto e Santos (2012), Bandeira de Mello e Cunha (2004) e Chermont e Rocha Pinto (2013).

\section{CONCLUSÃO}

O Quadro 2 traz o comparativo dos sete itens pesquisados entre a amostra de Jacobus, Souza e Bitencourt (2012) e a amostra desta pesquisa.

O que se verifica de mais relevante neste comparativo é que, na amostra brasileira, houve maior empenho em gerar teoria, com cerca de metade fazendo-o. Por outro lado, observou-se que metade da sua outra metade mostrou preocupação em deixar claro que estavam cientes de que este seria o desenlace natural esperado, ao explicitarem que este não era seu objetivo, justificando que os procedimentos da GT poderiam, de acordo com seus inventores, ser utilizados em um estudo sem necessariamente conduzir a uma teoria. Ou seja, de uma forma geral, pode-se dizer que os autores da amostra brasileira apresentaram maior fidelidade à proposta original de Strauss e Corbin (1967) do que a amostra dos autores estrangeiros.

Outro ponto que chama a atenção diz respeito à forte diferença na escolha da abordagem. Enquanto em sua totalidade os autores estrangeiros preferiram a quantitativa, todos os brasileiros abraçaram a abordagem qualitativa - neste caso, mostrando fidelidade à essência da GT, conforme Charmaz (2009). Por outro lado, essa fidelidade desapareceu em dois outros aspectos de extrema relevância para a garantia do atingimento do propósito último da GT de gerar teoria: os brasileiros não se mostraram tão preocupados em garantir a confiabilidade das análises nem em fazer uso constante da comparação. Já no que diz respeito ao empenho no detalhamento do processo de codificação e de análise dos dados e das evidências, se poucos artigos da amostra 
brasileira demonstraram este tipo de compromisso, pelo menos alguns o fizeram, enquanto Jacobus, Souza e Bitencourt (2012) não a detectaram em sua pesquisa.

QUADRO 2 - Itens pesquisados, resultados em Jacobus, Souza e Bitencourt (2012), e resultados nesta pesquisa

\begin{tabular}{|c|c|c|}
\hline Itens pesquisados & $\begin{array}{l}\text { Resultados em Jacobus, } \\
\text { Souza e Bitencourt (2012) }\end{array}$ & Resultados nesta pesquisa \\
\hline Produção de teoria plena & $\begin{array}{l}\text { Não houve: a "quase } \\
\text { totalidade" deles produz } \\
\text { apenas "aproximações } \\
\text { teóricas" (p. 10) }\end{array}$ & $\begin{array}{l}\text { Seis dos } 11 \text { artigos ( } 55 \% \text { da amostra) } \\
\text { não geraram teoria. Dentre estes, três } \\
\text { declaram explicitamente que sua } \\
\text { finalidade não era gerar teoria. }\end{array}$ \\
\hline $\begin{array}{l}\text { Justificativas para o uso da } \\
\text { GT como meio de pesquisa }\end{array}$ & $\begin{array}{l}\text { a) Ela garante que será } \\
\text { possível gerar teoria, e que } \\
\text { essa, por sua vez, não será } \\
\text { trivial; } \\
\text { b) Ela é “(...) particularmente } \\
\text { adequada em áreas em que o } \\
\text { desenvolvimento teórico ainda } \\
\text { é muito limitado" (p. 8); } \\
\text { c) Ela possui rigor especial no } \\
\text { que tange à "(...) coleta, } \\
\text { análise dos dados e } \\
\text { consequente geração de teoria" } \\
\text { (p. 8); } \\
\text { d) Ela é adequada para ser } \\
\text { aplicada a fenômenos que são } \\
\text { altamente determinados pelo } \\
\text { contexto organizacional em } \\
\text { que estão inseridos, onde se } \\
\text { destacam as percepções dos } \\
\text { sujeitos que vivem esse } \\
\text { fenômeno. }\end{array}$ & $\begin{array}{l}\text { Os motivos da escolha da GT nos } \\
\text { casos dos artigos que não visavam a } \\
\text { gerar teoria foram variados (afinidade } \\
\text { filosófica, pragmatismo da lógica } \\
\text { abdutiva, adequação para analisar } \\
\text { processos), inclusive eventualmente } \\
\text { contraditórios com o fato de não } \\
\text { terem gerado teoria (existência de } \\
\text { pouca teoria a respeito, adequação do } \\
\text { meio ao alcance do objetivo final). }\end{array}$ \\
\hline $\begin{array}{c}\text { Preocupação com a } \\
\text { confiabilidade das análises }\end{array}$ & $\begin{array}{l}\text { Sim, com 64\% da amostra } \\
\text { referindo-se direta ou } \\
\text { indiretamente à triangulação } \\
\text { dos dados. }\end{array}$ & $\begin{array}{c}\text { Apenas quatro artigos }(36 \% \text { da } \\
\text { amostra) referiram-se explicitamente } \\
\text { a esta preocupação. }\end{array}$ \\
\hline $\begin{array}{c}\text { Empenho no detalhamento } \\
\text { do processo de codificação e } \\
\text { de análise dos dados e das } \\
\text { evidências }\end{array}$ & Não houve. & $\begin{array}{l}\text { Ocorreu em três artigos ( } 27 \% \text { da } \\
\text { amostra). }\end{array}$ \\
\hline $\begin{array}{l}\text { Uso constante da } \\
\text { comparação }\end{array}$ & $\begin{array}{c}\text { Presente "(...) em quase todos } \\
\text { os artigos" (p. 9) }\end{array}$ & $\begin{array}{l}\text { Ocorreu em quatro artigos ( } 36 \% \text { da } \\
\text { amostra). }\end{array}$ \\
\hline Tipo de abordagem utilizada & Quantitativa & Qualitativa \\
\hline $\begin{array}{c}\text { Utilização da literatura } \\
\text { existente como gênese para a } \\
\text { formulação do problema de } \\
\text { pesquisa }\end{array}$ & Verificado em $98 \%$ da amostra & $\begin{array}{l}\text { Ocorreu em oito artigos ( } 72 \% \text { da } \\
\text { amostra). }\end{array}$ \\
\hline
\end{tabular}

Fonte: Elaboração própria 
E, finalmente, em um ponto houve convergência no caso de ambas as amostras: a maior parte dos artigos de ambas demonstrou ter utilizado a literatura existente como gênese para a formulação do problema de pesquisa.

O que se conclui é que, por mais que convergências e divergências tenham sido encontradas neste estudo comparativo, a palavra final da matriz inspiradora Jacobus, Souza e Bitencourt (2012) permanece: a GT não é utilizada de forma única, embora seus princípios básicos sejam respeitados pelos autores.

Aqui vale uma palavra a mais a respeito deste resultado, resgatando uma referência de peso para auxiliar na presente reflexão: o trabalho de Suddaby (2006). Este autor contribui de maneira inequívoca à pesquisa sobre a GT conforme expõe algumas concepções errôneas atribuídas à técnica, compiladas ao longo de sua atividade como avaliador do respeitado Academy of Management Journal: o uso da GT não implica ignorar a literatura nem significa a apresentação de dados brutos; a GT não é testagem de teoria, nem análise de conteúdo, nem contagem de palavras; a GT não é simplesmente aplicação rotineira de técnicas mecânicas, assim como não é perfeita nem fácil.

De fato, a simples avaliação de cada um destas concepções a diversas colocações dos autores dos 11 artigos da amostra estudada neste artigo mostra que vários deles caíram, em maior ou menor grau, em uma ou mais destas "armadilhas". Por exemplo, Ikeda e Bacellar (2008, p. 143) dizem que "Embora a finalidade da GT seja a construção de teorias, sua utilização não necessariamente precisa ficar restrita apenas aos pesquisadores que têm esse objetivo", assim como Bacellar e Ikeda (2007, p. 153) afirmam que "[...] seus procedimentos $[d a G T]$ podem ser utilizados especificamente em um estudo sem necessariamente conduzir a uma teoria", e Petrini e Pozzebon (2010, p. 362) informam claramente que, embora tenham usado a GT, o que construíram foi tão somente "modelo conceitual", e não uma teoria.

A propósito, profícuo contato virtual com Bandeira-de-Mello (2013) questionando as afirmações destes autores - já que, em Bandeira-de-Mello e Cunha (2012) nada há que as suporte - ajudou a esclarecê-las. De acordo com ele, este tipo de interpretação procede em parte, já que haveria uma forte tendência, na pesquisa em gestão, de utilizar apenas as técnicas de análise da GT baseadas nas comparações constantes, para identificar e validar categorias. Por outro lado, ele advertiu que 
Nesse caso, no entanto, não se pode dizer que se está utilizando a GT como estratégia de pesquisa, mas apenas utilizando sua técnica de análise de dados [grifo nosso]. A estratégia de pesquisa deve ser outra: estudo de caso, pesquisa quali básica, etnografia, pesquisa-acão, etc. Por isso, a GT não se encaixa (como estratégia de pesquisa) quando o objetivo não é gerar teoria a partir dos dados.

Nesta seara encaixa-se o ápice da contribuição acadêmica de Suddaby (2006), quando ele se preocupa em indicar que as raízes da opção pelo uso da GT frequentemente se perdem em uma espécie de deslumbramento dos pesquisadores quanto à perspectiva de virem a criar teoria. Em outras palavras, é como se uma leitura viesada dos princípios originais da GT propostos por Glaser e Strauss (1967) fosse deliberadamente adotada por pesquisadores que afirmam praticar a técnica (embora na verdade não consigam fazê-lo), como forma de alimentar-lhes o ego. Afinal, a GT não é fácil.

Algumas limitações se aplicam ao presente artigo. A primeira é que, muito frequentemente, os artigos que trazem os resultados de pesquisas empíricas publicados em periódicos indexados derivam de trabalhos maiores, tais como dissertações de mestrado ou teses de doutorado. Como estes periódicos via de regra colocam determinado limite de número de páginas para os artigos que lhes são submetidos, pelo bem da concisão os autores da amostra podem ter sido levados a omitir informações que teriam implicado diferentes conclusões por parte deste levantamento bibliométrico.

Da mesma forma, é possível que os resultados obtidos neste levantamento também tenham sido impactados pelo fato de os periódicos indexados não raro demandarem que os autores sigam determinado padrão de apresentação de artigos resultantes de pesquisas empíricas, classicamente composto de seis itens: introdução, referencial teórico, metodologia, resultados da pesquisa, conclusão, e sugestões de futuros estudos. Assim, alguns autores podem ter suposto que a submissão ao periódico obrigatoriamente implicava a obediência à apresentação do item de referencial teórico passo do qual a GT prescinde - anomalia que viria a ser interpretada como falha metodológica neste estudo bibliométrico.

A combinação destes fatores se constitui em limitação relevante deste levantamento bibliométrico, pois pode ter-lhe implicado viés uma vez que seus 
resultados basearam-se estritamente naquilo que a amostra estudada trouxe de forma explícita.

Ademais, a comparação, em termos de percentuais, dos resultados desta amostra brasileira com a amostra estudada por Jacobus, Souza e Bitencourt (2012) deve ser moderada pelo fato de a primeira ter-se composto de apenas 11 artigos, tendo em vista que quantificações percentuais neste caso naturalmente sofrem o viés do reduzido número absoluto.

De qualquer forma, o que esta pesquisa mostrou foi que, apesar do maior empenho dos brasileiros em gerar teorias substantivas, ou pelo menos em aproximaremse desta geração, tomando-se como base os 56 artigos das duas amostras conjuntamente foi baixo o esforço geral neste sentido. Pode-se hipotetizar que, apesar de a gênese da GT datar de antes da década de 1970, esta carência derive do ainda reduzido domínio deste meio de pesquisa por parte dos estudiosos de Administração de Empresas. Fica, portanto, a sugestão para que futuros estudos lhe mapeiem o uso em outros veículos de difusão de pesquisas acadêmicas, de forma a confirmar - ou não - este ponto.

\section{REFERÊNCIAS}

BACELLAR, F.; IKEDA, A. Ensinar Marketing na Visão de seus Professores. Revista O\&S, vol. 14, n. 42, 2007.

BANDEIRA DE MELlO, R.; CUNHA, C. Administrando o Risco: uma Teoria Substantiva da Adaptação Estratégica de Pequenas Empresas a Ambientes Turbulentos e com Forte Influência Governamental. RAC - Revista de Administração Contemporânea, vol 08, edição especial, 2004.

BANDEIRA-DE-MELLO, R.; CUNHA, C. Grounded Theory. In: GODOI, C.; BANDEIRA-DE-MELLO, R.; SILVA, A. Pesquisa Qualitativa em Estudos Organizacionais. São Paulo: Saraiva, 2. ed., 2012.

BANDEIRA DE MELLO, R. Dúvida sobre grounded theory [mensagem pessoal]. Mensagem recebida por <irene.troccoli@estacio.br> em 09 jun. 2013.

CHARMAZ, K. A construção da teoria fundamentada. São Paulo: Bookman, 2009 CHERMAN, A.; ROCHA PINTO, S. Valoração do conhecimento: significação e identidade na ação organizacional. RAE - Revista de Administração de Empresas, vol. 53, n. 2, mar-abr, 2013. 
CRUZ, B.; ZOUAIN, D. Atuação de consórcios de exportação brasileiros no segmento de moda praia. RAM - Rev. Adm. Mackenzie, v. 9, n. 2, 2008.

EGAN, T. M. Grounded theory research and theory building. Advances in Developing Human Resources, v. 4, n. 3, p. 277-295, 2002.

FREZATTI, F.; NASCIMENTO, A.; JUNQUEIRA, E.; RELVAS, T. Processo Orçamentário: uma aplicação da análise substantiva com utilização da grounded theory. Revista O\&S, vol. 18, n. 58, 2011.

GLASER, B.; STRAUSS, A. The discovery of Grounded Theory, Chicago: Aldine 1967.

GOULDING, C. Grounded Theory; A Practical Guide for Management, Business and Market Researchers, Sage, London, 2002.

GOULDING, C. Grounded theory, ethnography and phenomenology. A comparative analysis of three qualitative strategies for marketing research. European Journal of Marketing, vol. 39, n. 3/4, pp. 294-308, 2005.

HAIG, B. Grounded theory as scientific method. In: NEIMAN, A. Philosophy of education. Urbana: University of Illinois Press, 1995. p. 281-290.

IKEDA, A.; BACELLAR, F. Revelando e compreendendo o relacionamento professoraluno em Marketing. RAM - Rev. Adm. Mackenzie, vol.9, no.5, 2008

JACOBUS, A.; SOUZA, Y.; BITENCOURT, C. que Fazem Afinal os Pesquisadores que Praticam GroundedTheory? XXXVI Encontro da ANPAD. Anais... Rio de Janeiro (RJ), setembro, 2012.

MULLINS, J.; ROESSIER, R. Improving employment outcomes; perspectives of experienced counsellors regarding the importance of counselling tasks. Journal of Rehabilitation, Vol. 64 No. 2, pp. 12-18, 1998.

PETRINI, M.; POZZEBON, M. Integrating Sustainability into Business Practices: Learning from Brazilian Firms. BAR - Brazilian Administration Review,vol. 07, n. 04, oct-dec, 2010.

PINTO, M.; SANTOS, L. A grounded theory como abordagem metodológica: relatos de uma experiência de campo. Revista O\&S, vol. 19, n. 62, 2012.

SARAIVA, E.; CARRIERI, A.; AGUIAR, A.; BRITO, V. Um "Pas de Deux" da Estratégia com a Arte: as Práticas do Grupo Corpo de Balé. RAC - Revista de Administração Contemporânea, vol. 15, n. 06, nov-dez, 2011. 
SCHWANDT, T.A. Constructivist, interpretivist approaches to human enquiry. In Denzin, N.K. and Lincoln, Y.S. (Eds), Handbook of Qualitative Research, Sage, Thousand Oaks, CA, 1994.

STRAUSS, A.; CORBIN, J. Basics of qualitative research. Techniques and procedures for developing grounded theory. $2^{\mathrm{a}}$ ed. Thousand Oaks: Sage Publications, 1998.

SUDDABY, R. From the editors: what grounded theory is not. Academy of Management Journal, vol. 49, n. 4, p. 633-642, 2006.

VASCONCELOS, I.; PINOCHET, L. A tecnologia como forma de controle burocrático: uma análise crítica do uso dos sistemas de segurança de informática em uma empresa de alta tecnologia. RAM - Rev. Adm. Mackenzie, v. 3, n. 1, 2002.

ZANIN, E.; BACH, T.; WALTER, S. Grounded Theory em estudos organizacionais: análise das metodologias, dos temas e de suas finalidades. XV Semead. Anais... São Paulo (SP), outubro, 2012.

ZILBER, M.; PEREZ, G.; LEX, S. Inovação tecnológica e obtenção de vantagens competitivas: um estudo duplo qualitativo na indústria brasileira de equipamentos eletromédicos. Revista O\&S, vol. 16, n. 51, 2009.

\section{Como citar este documento:}

TROCCOLI, Irene Raguenet. E os pesquisadores brasileiros que praticam grounded theory: o que fazem? Rev. digit. bibliotecon. cienc. inf., Campinas, SP, v.12, n.2, p.20-37, maio/ago. 2014. ISSN 1678-765X. Disponivel em: <http://www.sbu.unicamp.br/seer/ojs/index.php/rbci>. Acesso em: 30 maio 2014. 